\title{
CENTRAL NECROSIS FOLLOWING CONTUSION TO THE SHEEP'S SPINAL CORD
}

\author{
By John D. Yeo, M.B., B.S., D.P.R.M., Stephanie Stabback, B.Sc., Dip.Ed. and \\ BART MCKenzIE, M.B., B.S.* \\ Spinal Unit, Royal North Shore Hospital of Sydney and \\ * School of Underwater Medicine, The Royal Australian Navy
}

Abstract. This paper presents the results of a study on the pathological changes associated with post traumatic central spinal cord necrosis.

Key words: Necrosis; spinal cord.

\section{Introduction}

EXPERIMENTAL work supports the concept that progressive damage to central grey matter as well as the white matter of the spinal cord occurs after the initial bruising injury. Toxic substances may be released from the injured neurones or transported to the area causing further tissue damage either directly or indirectly by producing further ischaemia. Partial reversal could possibly be achieved by blocking the release of any noxious chemical (Allen, I9I I; Albin et al., I968; Ducker \& Hamit, I969; Kelly et al., 1970; Osterholm \& Mathews, 1972; Kobrine, 1975; Yeo \& Payne, I975; Kobrine et al., 1976). With various surgical and nonsurgical techniques used in the experimental animal, e.g. local saline perfusion, intramuscular and intrathecal steroids, myelotomy, monoamine inhibition, hyperbaric oxygen and $\mathrm{H}_{2}$ histamine antagonists, it has been possible to modify in animals what otherwise would be extensive cystic necrosis with paralysis and loss of sensation below the level of the lesion (Tomasula et al., I969; White \& Albin, 1970; Dohrmann et al., 1972; Tator, 1972; Osterholm, 1974; Yeo et al., 1975).

There have been conflicting reports on the pathogenesis of these progressive changes in the microvasculature and the nerve fibres of the traumatised spinal cord (Wagner et al., I97I; Dohrmann et al., 1973). The reported fourfold increase in the levels of noradrenaline and the low levels of dopamine within I hour (Osterholm \& Mathews, 1972) have not been substantiated in recent work by other laboratories (Naftchi et al., I974; Hinwood, Kidman \& Yeo, 1975). Serotonin and histamine have also been implicated (Kobrine et al., I976; Zivin et al., 1976).

The data suggest that ischaemia plays a major role in the pathogenesis of post-traumatic central cord necrosis and results in the associated loss of motor function and sensation below the level of the lesion. Supporting this theory are the reports that hyperbaric oxygen improves the motor recovery in paraplegic animals (Hartzog et al., I969; Kelly et al., I972; Yeo et al., 1976).

\section{Aims}

(I) To study the pathogenesis of post-traumatic central cord necrosis in the sheep's spinal cord; (2) to assess the level of motor recovery in sheep with a significant degree of post-traumatic necrosis in grey and white matter of the spinal cord; (3) (i) to compare the recovery of motor power after controlled contusion to the 
sheep's spinal cord following treatment with methyl prednisolone, alphamethyl paratyrosine and hyperbaric oxygen, and (ii) to compare the histopathology found in the spinal cords of these animals at the level of the lesion.

\section{Materials and Methods}

The sheep were anaesthetised with intravenous sodium pentobarbitone and a laminectomy performed exposing the lower thoracic spinal cord. Spinal cord contusion was produced by dropping a $50 \mathrm{~g}$ weight from a height of $20 \mathrm{~cm}$ within a Teflon tube on to an impactor placed over the spinal cord at the level of Tio vertebra, delivering an impact injury of $19.88 \mathrm{~g} / \mathrm{cm}$ force per $\mathrm{mm}^{2}$ (Yeo et al., I97 I). The macroscopic appearance of each spinal cord was recorded before and after injury with photography and the degree of apparent cord swelling and bruising within 5 minutes studied. In a number of animals isotope and contrast myelography were used to monitor the extent and duration of spinal cord swelling (Yeo \& Collins, 1974). An electrical stimulus (2-5 volts for 0.05-0.0I ms) repeated at I second intervals was applied to the dorsal surface of the spinal cord I $\mathrm{cm}$ above and below as well as at the level of the injury and the reflex motor response compared before and after injury.

Those animals in the clinical study were placed after the procedure in supportive slings and nursed for periods of 8 and 13 weeks. Each animal was removed from the sling daily to help prevent trophic skin ulceration and encourage voluntary movements. Early development of a reflex neurogenic bladder within 24 hours avoided the necessity of catheterisation of the bladder. Animals in the control and treated groups were examined clinically at least three times weekly. The motor power was assessed above and below the stifle joint (femoro-tibial) and the following classification used for assessment of motor power; o, completely absent; I, some voluntary movement against gravity; 2, movement against resistance; and 3, normal. A normal hind limb would rate as 6 so that both hind limbs with normal motor power above and below the stifle joints would total I2. In each group the mean recovery was then recorded each week and the observations classified into one of the following four categories; A(I-4) = mild; $\mathrm{B}(5,6)=$ moderate; $\mathrm{C}(7,8)=$ good; $\mathrm{D}(9-\mathrm{II})=$ excellent. The difference in the recovery rates between the control and treated animals was then tested using the exact probability test for a $2 \times 4$ contingency table.

The animals which received intrathecal methyl prednisolone $(40 \mathrm{mg})$ within I hour of the injury survived for periods up to 13 weeks and the mean recovery was compared to the control group.

Those animals which received alpha-methyl paratyrosine, an anti-tyrosine hydroxylase agent, intravenously over a period of 60 minutes commencing is minutes after injury, were allowed to survive for 13 weeks and the recovery compared to the control group.

Those animals which received hyperbaric oxygen at 3 atmospheres commencing 30 minutes after the injury for 90 minutes, survived for 8 weeks and the recovery was compared with the recovery in the control group of animals over the same period.

Autopsies were carried out on all animals in both treated and untreated groups. The macroscopic appearance of the injured spinal cord after fixation in formol saline Io per cent was recorded with photography. Sections of the spinal cord were taken at the level of the injury, I $\mathrm{cm}$ above and $\mathrm{I} \mathrm{cm}$ below. Tissue 
blocks were prepared and sections stained using Luxol fast blue and Van Gieson staining.

The degree of central cord necrosis and demyelinisation in each spinal cord was recorded using transmitted light or dark field photography techniques.

\section{Results}

Although the contusion to the spinal cord in the experimental animal was standardised the degree of injury varied macroscopically and microscopically. The variations in the degree of congestion, extravasation, subdural haemorrhage and axonal swelling have been described previously (Yeo et al., 1975). There are sequential pathological changes in the moderately contused spinal cord with dynamic histological changes in both grey and white matter occurring within 2 days of the injury. Without treatment, marked central cord necrosis occurred at the level of the lesion with microcysts and demyelinisation evident in the surrounding white matter (see Figs. I and 2).
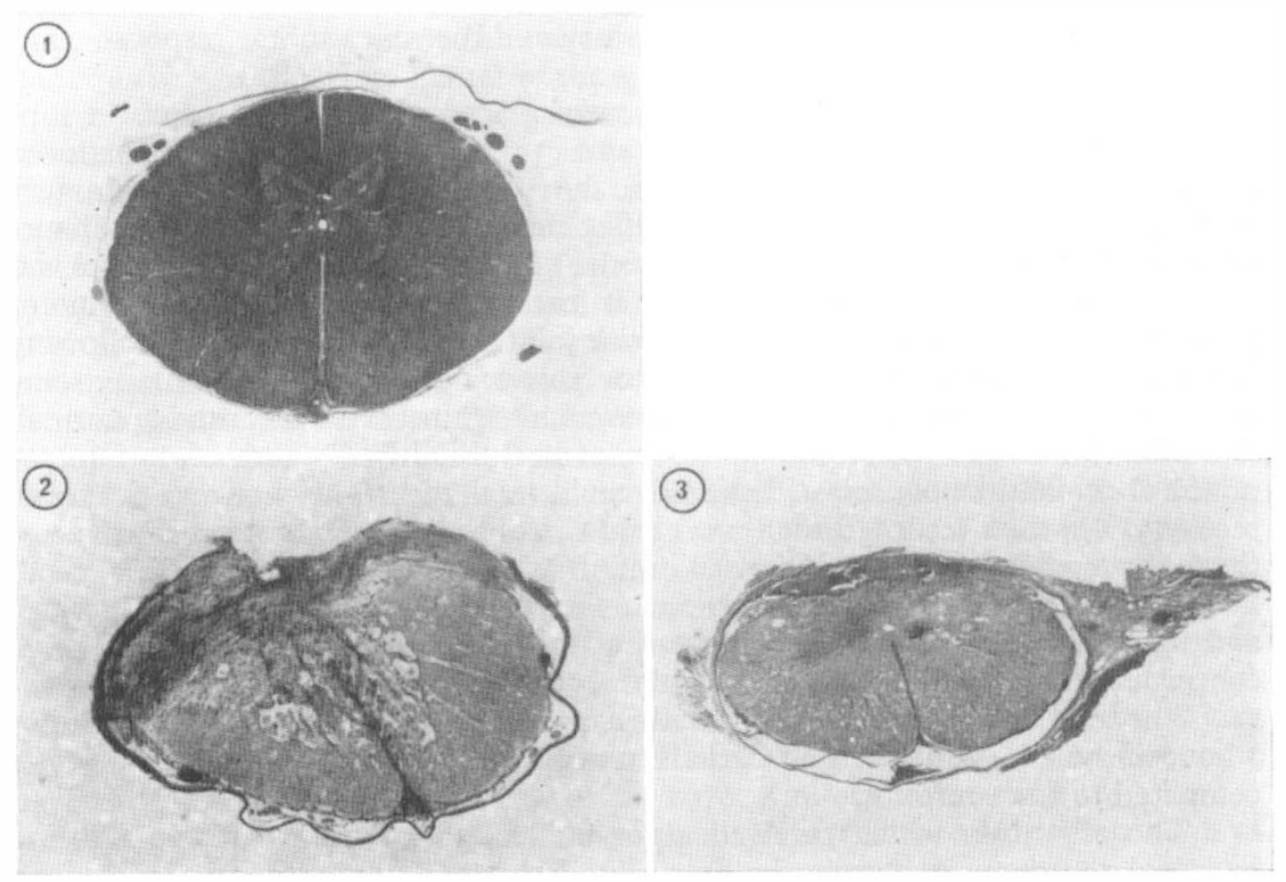

FIG. I

Cross-section of the normal sheep's spinal cord (Tio) stained with Luxol fast blue and Van Gieson stains.

FIG. 2

Central cystic necrosis with demyelinisation in the lateral and anterior columns at the level of the lesion 8 weeks after the injury (L.F.B. stain).

FIG. 3

Less cystic degeneration is seen in the cross-section of the spinal cord at the level of the lesion 8 weeks after the injury (animal treated with hyperbaric oxygen). 
In all the untreated control animals studied at 8-week and I3-week intervals after injury, there was extensive demyelinisation in the white matter with varying degrees of fibrosis, gliosis and extensive central cystic degeneration. These pathological changes were localised to within $2 \mathrm{~cm}$ of the impact site. There was little evidence of Wallerian degeneration although demyelinisation in the dorsal spino-cerebellar tracts was often evident above the level of the lesion. Even with this severe degree of degeneration there was significant motor recovery in the untreated animals. All of these animals in the control groups recovered at least anti-gravity movements above and below the stifle joint. No animal in control or treated groups had return of total motor function in the hind limbs.

In the group of animals treated with intrathecal methyl prednisolone ('Depo medrol') there was no significant improvement in the recovery of motor function over I3 weeks. The degree of central cystic necrosis and demyelinisation appeared similar to that found in the untreated control animals. These results have been previously reported (Yeo et al., 1975).

In the series of animals treated with AMT there was a significant improvement in motor function with less central cystic necrosis and microcystic changes in the white matter (Yeo et al., 1975).

In animals treated with hyperbaric oxygen there was a significant improvement of motor recovery over a period of 8 weeks after the injury. At the level of the lesion there was less central cystic change and microcyst formation in the anterior and lateral columns (see Fig. 3). The clinical recovery in a small preliminary series has been reported (Yeo et al., 1976), and the results of the second series of treated animals confirm that there is improved motor recovery following treatment with hyperbaric oxygen (Fig. 4). On statistical analysis there was a significant improvement at all weekly intervals except at the 5 th week.

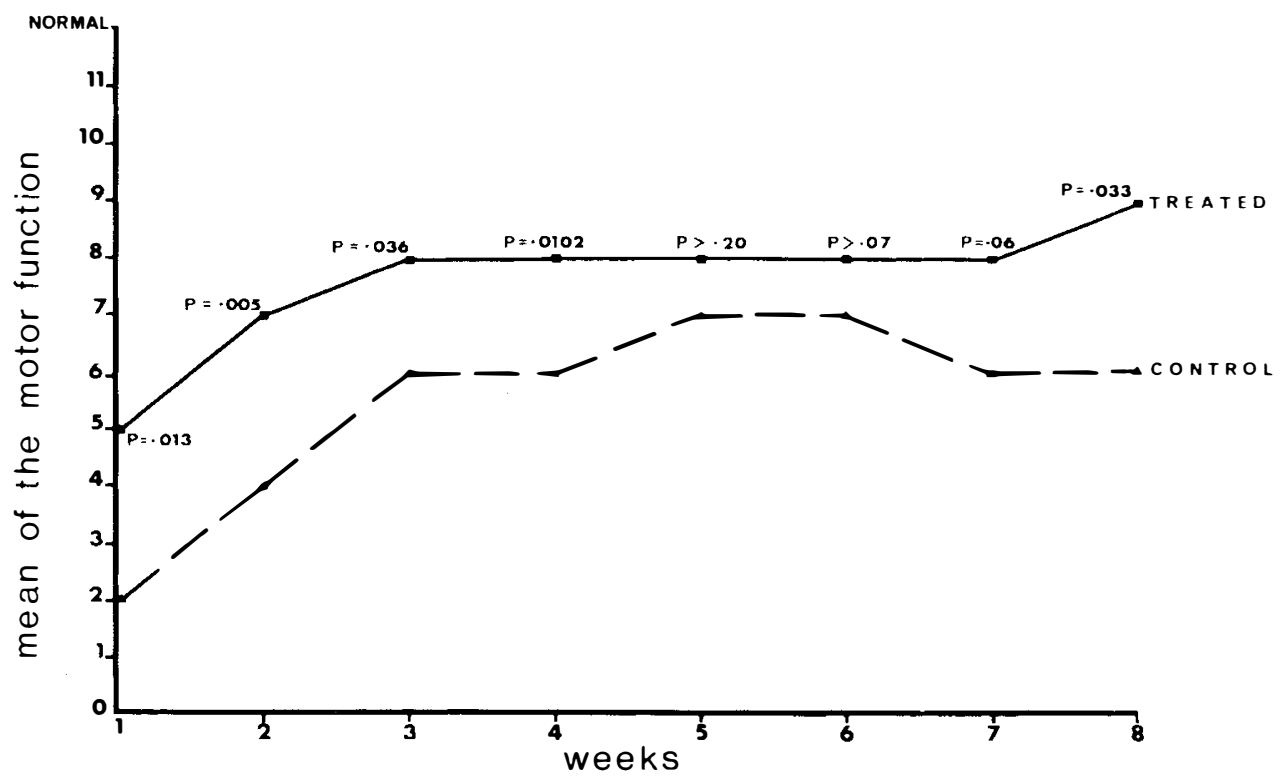

FIG. 4

Graph showing recovery of motor function in the group of eight hyperbaric oxygen treated animals compared to the recovery in the control group. 


\section{Discussion}

There are difficulties comparing the changes within the injured spinal cord of the sheep and the post-traumatic change in the spinal cord of man. The corticospinal tract reaches its highest genetic development in man and in the primates, and is related to the development of digital or skilled movements. In man the pyramidal tract represents 30 per cent of the total white matter in the spinal cord; 20 per cent in the monkey and Io per cent in the dog. Also in man 50 per cent of the lateral cortico-spinal tract runs to the cervical segments, 20 per cent to the thoracic and 30 per cent to the lumbar segments, whereas in other animal species there appears to be a predominant distribution to the fore-limbs suggesting direct cortical control of these extremities (Palmer, 1965). In sheep the pyramidal tract disappears after the 3 rd or 4 th cervical segment. Lassek (1942) has estimated that compared with one million or so fibres in the cortico-spinal pathway of man, the sheep has only two hundred and fifty thousand. There is a short descending relay system of fibres in the lateral and ventral columns of the sheep (Chomiak et al., I960) and this tract is probably of greater importance than the cortico-spinal tract itself. Injury to the dorsal surface of the sheep's spinal cord should cause less disturbance of motor power than injury to the ventral surface of the cord. In ungulates, 50 per cent of the fibres remain in the ventral tract and it is these fibres or their short relay successors which play an important role in motor function, particularly of the hind limbs. In the sheep there is therefore significant return of motor function in the hind limbs even though the injury produces extensive central cystic degeneration and demyelinisation of surrounding white matter at the level of the lesion.

Pain sensations could not be accurately recorded in the sheep due to the presence of spinal reflex activity within 2 or 3 days of the injury. Sheep also tend to have a hypersensitivity to pain after a thoraco-lumbar spinal cord lesion, said to be associated with hyperactivity of the internuncial fibres (Fulton, 1950). The phenomenon of spinal walking is well known and will occur even when the hind limbs of an animal are deprived of the efferent supply, and the paraplegic sheep can wag its tail if the tail region is stimulated directly.

Freeman (I952) has commented 'It requires very little neural tissue which has escaped spinal cord injury to give a considerable amount of voluntary control in the hind limbs'.

Because of the difficulties encountered in determining motor power in the experimental animal, the clinical recovery must be correlated with the pathology found in the injured spinal cord.

There have been conflicting reports on the pathogenesis of the early progressive changes in the microvasculature and nerve fibres of the contused spinal cord in the experimental animal. Fluorescent microscopy (Wagner et al., 197I) has shown that time related formation of extravasation and oedema occurs within the central grey matter. Dohrmann et al. (1973) demonstrated marked reduction in perfusion of the central grey matter within 8 hours. Fried and Goodkin (I97I) demonstrated progressive lack of perfusion within the cord and this severe disturbance of haemodynamics was still evident 24 hours after the injury. Turnbull (I97I) described central vessels of the spinal cord as susceptible to stretching and compression by antero-posterior forces, and Green, Wagner and Bucy (I97I) reported the development of oedema in cats, initially in the grey and later in the white matter within the first 8 hours of the injury. After I hour the oedema appeared primarily 
to involve the grey matter but by 4 hours the white matter immediately adjacent to the grey matter was also involved.

Osterholm and Mathews (I97I, 1972) were the first to suggest that local accumulation of norepinephrine followed injury and would result in progressive damage to neurones. Norepinephrine would also cause further ischaemia by vasoconstriction of small vessels. Although other workers have not been able to confirm this rise of noreadrenaline (Hinwood et al., I974; Vise et al., 1974), hypoxia has been shown to contribute significantly to haemorrhagic necrosis (Locke et al., I971; Kelly et al., 1972).

Progressive disturbance of haemodynamics leading to further local hypoxia of the nerve tissue has been well recognised and suggested as the reason for extension of the neurological deficit within hours of the spinal cord injury (Barnes, I948; Schneider, I958; Bedbrook, I966; Osterholm \& Mathews, I972; Vise et al., 1974; Yeo et al., 1975). Kobrine and Martins (1974) demonstrated hyperperfusion of the lateral white matter of Rhesus monkeys after injury and suggested that this finding disproved the notion of spreading ischaemia as a cause of paraplegia.

Ducker and Hamit (1969) produced a contusion injury in beagles and recorded that parenteral administration of steroids by intramuscular injection was of value in preventing permanent paraplegia. Black and Markowitz (I97I) suggested that steroids enhanced the functional recovery in monkeys, although Yeo et al. (1975) were not able to show any significant improvement in sheep treated with intrathecal methyl prednisolone.

There was, however, a significant improvement in the animals treated with alpha-methyl paratyrosine suggesting that local norepinephrine may play a role in the progressive necrosis within the injured segment of spinal cord. The time interval following the trauma must be important and further work on monoamine turnover would appear to be necessary to elucidate this complex problem. It is of interest that recently histamine and 5-hydroxytryptamine have again been suggested as possibly involved in the progressive damage to the neurones of the contused spinal cord (Zivin et al., I976; Kobrine et al., 1976).

The reversibility of graded spinal cord trauma in the experimental animal after three exposures to IOO per cent oxygen at 3 atmospheres absolute pressure was reported by Hartzog et al. (I969). The treatment was given 3, I I and 2 I hours after the injury for 45 minutes' duration. Significant clinical improvement occurred and the neurological status remained stable for I month. Kelly et al. (I972) reported significant recovery of function in injured dogs treated with hyperbaric oxygen. The degree of recovery was stated to be equal to that after treatment with glucocorticoids, intrathecal injection of methyl prednisolone, and hypothermia. Yeo et al. (1976) reported encouraging results of hyperbaric oxygen therapy to control the degree and duration of paraplegia after recent spinal cord injury in sheep. The improved motor recovery over 8 weeks was evident in sheep treated with hyperbaric oxygen at 3 atmospheres for 90 minutes commencing 30 minutes after the injury. The results in this more recent series also support the suggestion that experimental contusion produces an ischaemic lesion which can be partially reversed by (i) intravenous administration of alpha-methyl paratyrosine or (ii) exposure of the animal to hyperbaric oxygen within 2 hours of the injury. In both series there is less central cord necrosis in the treated animals.

Renal toxicity of alpha-methyl paratyrosine prohibits its use in the recently injured paraplegic or quadriplegic patient; hyperbaric oxygen now appears to be a form of treatment for trial in the recently injured paraplegic patient. 


\section{SUMMARY}

The paper presents the results of a study on the pathological changes associated with post-traumatic central spinal cord necrosis. The degree of motor recovery in sheep with a controlled contusion injury to the spinal cord is compared with the recovery in sheep treated with intrathecal methyl prednisolone, alphamethyl paratyrosine or hyperbaric oxygen. The degree of central cord cystic necrosis and the extent of demyelinisation in the surrounding white matter is compared in each group of treated animals. The success in improving motor recovery and controlling the degree of cord degeneration with alpha-methyl paratyrosine and hyperbaric oxygen suggests that ischaemia plays a significant role in the experimental animal with a contusion injury to the spinal cord.

\section{RÉSUMÉ}

L'article présente les résultats d'une étude des changements pathologiques associés avec la nécrose post-traumatique de la moelle épinière centrale. On compare le degré de rétablissement de la motricité chez les moutons avec une lésion contrôlée de meurtrissure à la moelle épinière avec la guérison des moutons traités avec du prednisolone de méthyl intrathécal, avec du paratyrosine "alpha-methyle" ou avec de l'oxygène sous pression excessive. Pour chaque groupe des animaux traités on compare le degré de la nécrose cystique de la moelle épinière centrale et l'étendue de la démyélinisation dans la matière blanche environnante. Puisqu'on a réussi à faire des progrès au rétablissment de la motricité et à la maîtrise du degré de la dégénération de la moelle épinière en se servant de paratyrosine "alpha-methyle" et d'oxygène sous pression excessive, il se présente que c'est l'ischémie qui joue un rôle significatif quand il s'agit d'un animal d'essai avec une lésion de meurtrissure à la moelle épinière.

\section{ZUSAMMENFASSUNǴ}

Dieser Artikel enthält die Ergebnisse einer Untersuchung der pathologischen Veränderungen im Zusammenhang mit einer post-traumatischen Nekrose des zentralen Rückenmarkes. Es werden Vergleiche angestellt zwischen dem Ausmaß der motorischen Gesundung bei Schafen mit einer Quetschverletzung des Rückenmarks, deren Ausbreitung eingeschränkt werden kann, und dem Ausmaß der Gesundung bei Schafen, welche mit intra-thekalem Methyl-Prednisolonum, mit Alpha-Methyl-Paratyrosin oder mit Sauerstoff unter Überdruck behandelt werden. Der Grad der Blasen-Nekrose des zentralen Rückenmarks und das Ausmaß der Entmarkung in der umgebenden weißen Substanz wird bei jeder Gruppe der behandelten Tiere einer vergleichenden Betrachtung unterzogen. Der Erfolg bei den Bestrebungen, den motorischen Gesundungsprozess zu vervollkommnen und der Entartung des Rückenmarks Einhalt zu gebieten, indem man Alpha-Methyl-Paratyrosin und Sauerstoff unter Überdruck anwendet, legt die Vermutung nahe, dass bei Versuchstieren mit einer Quetschverleztung am Rückenmark die örtliche Blutleere eine wesentliche Rolle spielt.

Acknowledgements. This research project has been continued with assistance from the National Health and Medical Research Council and support from the Spinal Injuries Research Fund. We gratefully acknowledge the assistance of the Royal Australian Navy and the contributions made by many colleagues including Research Assistants, $\mathrm{Mr} \mathrm{R}$. Kearns, Mr R. Sherwood, Mr C. Liddy and Mr B. Brown, Technical Officer of the Royal North Shore Hospital. Dr George Cooney, Department of Mathematical Statistics, University of Sydney has provided the statistical analysis and $\mathrm{Mr}$ Ron Israel and $\mathrm{Mr}$ Harry Ugandi developed special techniques to photograph the spinal cord sections.

\section{REFERENCES}

Albin, M. S., White, R. J., Acosta-Rua, G. \& YAshon, D. (1968). Study of functional recovery produced by delayed localized cooling after spinal cord injury in primates. f. Neurosurg. 29, I I3-I20. 
Allen, A. R. (I9II). Surgery of experimental lesion of spinal cord equivalent to crush injury of fracture dislocation of spinal column: a preliminary report. F. American Med. Assoc. 57, 878-880.

BARNES, R. (I 948). Paraplegia in cervical spinal injuries. F. Bone E Foint Surg. 30B, 234-244.

BEDBRook, G. M. (1966). Pathological principles in the management of spinal cord trauma. Paraplegia, 4, 43-56.

BlaCk, P. \& MARKowiTZ, R. S. (I97I). Experimental spinal cord injury in monkeys: comparison of steroids and local hypothermia. Surg. Forum, 22, 409-4II.

Chomiak, M., Lewandowski, M., LUtNicki, W. \& Milart, Z. (I960). Versuche zur Bestimmung der Rückenmarkbahnen beim Schaf mittels der Degenerationsmethode. Ann. Univ. M. Curie-Sklofowska, D.D. I5, 65.

Dohrmann, C. J., Wagner, F. C. JR. \& BUCY, P. C. (I972). Transitory traumatic paraplegia: electron microscopy of early alterations in myelinated nerve fibers. $\mathcal{F}$. Neurosurg. 36, 407-4I5.

DohrmanN, G. J., Wick, K. M. \& Bucy, P. C. (I973). Spinal cord blood flow patterns in experimental traumatic paraplegia. F. Neurosurg. 38, 52-58.

DUCKER, T. B. \& HAMIT, H. F. (1969). Experimental treatments of acute spinal cord injury. f. Neurosurg. 30, 639-697.

FREEMAN, L. W. (I952). Return of function after complete transection of the spinal cord of the rat, cat and dog. Annals of Surgery, 136, 193.

FrIED, L. C. \& GoodKIN, R. (I97I). Microangiographic observations in the experimentally traumatized spinal cord. F. Neurosurg. 35, 709-7I4.

Fulton, J. F. (1950). A Textbook of Physiology, I6th edition. Saunders, Philadelphia.

GreEN, B. A., WAGNER, F. C. JR. \& BUCY, P. C. (I97I). Edema formation within the spinal cord. Trans. Amer. Neurol. Assoc. 96, 244-245.

Hartzog, J. T., Fisher, R. G. \& SNOw, C. (I969). Spinal cord trauma; effect of hyperbaric oxygen therapy. Proc. Annu. Clin. Spinal Cord Inj. Conf. 1 7, 70-71.

Hinwood, B., YEO, J. D. \& Kidman, A. D. (I974). Catecholamine levels in the sheep's spinal cord following trauma. Proc. of the Australian Biochemistry Society, 7, 29.

Hinwood, B. G., Yeo, J. D. \& Kidman, A. D. (I975). Molecular pathology of spinal injuries. The monoamine hypothesis. Proc. Aust. Biochem. Soc. 8, 60.

Kelly, D. L., Lassiter, K. R. L., Calogero, J. A. \& Alexander, E. (I970). Effects of local hypothermia and tissue oxygen studies in experimental paraplegia. $\mathcal{F}$. Neurosurg. 33, 554-563.

Keliy, D. L., Lassiter, K. R. L., Vonsgsvivut, A. \& Smith, J. M. (I972). Effects of hyperbaric oxygenation and tissue oxygen studies in experimental paraplegia. $\mathcal{F}$. Neurosurg. 36, 425-429.

Kobrine, A. I. \& Martins, A. N. (1974). Spinal cord blood flow and neurological dysfunction. Lancet, April 27.

KobRINE, A. I. (I975). The neuronal theory of experimental traumatic spinal cord dysfunction. Surg. Neurol. 3, 21.

Kobrine, A. I., Doyle, T. \& Rizzoli, H. (1967). Further studies on histamine in spinal cord injury and post traumatic hyperemia. Surg. Neurol. 5, IOI-IO3.

LASSEK, A. M. (1942). The pyramidal tract; a fibre and numerical analysis in a series of nondigital mammals (ungulates). F. Comp. Neurol. 77, 399.

Locke, G. E., YASHON, D. \& FELDMAN, R. A. et al. (I97I). Ischaemia in primate spinal cord injury. F. Neurosurg. 34, 6I4-6I7.

Naftchi, N. E., Demeny, M., Decrescito, V., Tomasula, J., Flamm, E. \& Campbell, J. (1974). Biogenic amine concentration in traumatised spinal cords of cats. $\mathcal{F}$. Neurosurg. 40, $52-57$.

Osterholm, J. L., Mathews, G. F. \& Irvin, J. D. et al. (I97I). A review of altered norepinephrine metabolism attending severe spinal injury: results of alpha methyl tyrosine treatment and preliminary histofluorescent studies. Proc. Veterans Admin. Spinal Cord Inj. Conf. 18, I7-2 I.

Osterholm, J. L. (1974). The pathophysiological response to spinal cord injury-current status. F. Neurosurg. 40, 5-33.

OSTERHOLM, J. L. \& MATHEWS, G. J. (1972). Altered norepinephrine metabolism following experimental spinal cord injury. I. Relationship to haemorrhagic necrosis and postwounding neurological deficits. F. Neurosurg. 36, 386-394.

OSTERHOLM, J. L. \& MATHEWs, G. J. (I972). Altered norepinephrine metabolism following experimental spinal cord injury. II. Protection against traumatic spinal cord haemorrhagic necrosis by norepinephrine synthesis blockade with alpha methyl tryosine. f. Neurosurg. 36, 395-40I.

I $4 / 4-D$ 
Palmer, A. C. (1965). Introduction to Animal Neurology, ist edition. Blackwell Scientific Publications, Oxford.

Salthouse. (I965). Luxol fast blue for staining phospholipids. F. Histochem. Cytochem. 13, 133 .

SCHNEIDER, R. D. (I958). The syndrome of acute central cervical spinal cord injury. f. Neurol. Neurosurg. Psychiat. 21,2 I6.

TATOR, C. H. (1972). Acute spinal cord injury: a review of recent studies of treatment and pathophysiology. C.M.A. Fournal, July 22, 107, I43-150.

Tomasula, J. J., DeCRescito, V. \& Goodkin, R. et al. (I969). A survey of the management of experimental spinal cord trauma. Proc. Annu. Clin. Spinal Cord Inj. Conf. 7I, I2-I6.

Turnbull, I. M. (I97I). Microvasculature of the human spinal cord. $\mathcal{F}$. Neurosurg. 35, I4I-I 47 .

VISE, W. M., YASHON, D. \& HUNT, W. E. (I974). Mechanisms of norepinephrine accumulation within sites of spinal cord injury. F. Neurosurg. 40, 76-82.

WAGNer, F. C. JR., GreEN, B. A. \& BuCY, P. C. (I97I). Spinal cord edema associated with paraplegia. Proc. Clin. Spinal Cord Injury Conf.

White, R. J. \& Albin, M. S. (I970). Spine and spinal cord injury. In: Gurdjian, E.S., Lane, W. A., Patrick, L. M., (eds): Impact Injury and Crash Protection. Charles C. Thomas, Publisher, Springfield, Ill., pp. 63-85.

Yeo, J. D., Payne, W. \& Collins, L. T. (I97I). Controlled experimental contusion of the spinal cord of sheep. Proceedings of the Surgical Research Society of Australasian Scientific Meeting. Aust. E N.Z. F. Surgery, 4I, no. I, 89-90.

Yeo, J. D. \& Collins, I. (I974). The place of isotope myelography in the definition of spinal cord swelling following trauma. Aust. $\mathcal{E}$ N.Z. F. Surgery, 44, no. 3, 292-298.

Yeo, J. D. \& PAYNE, W. H. (I975). Sequential pathological changes seen in controlled trauma to the spinal cord of the sheep. Ann. Meeting Royal College of Pathologist. of Aust., Aukland, N.Z. F. Pathology, 7, no. I, 66.

Yeo, J. D., Payne, W., Hinwood, B. \& Kidman, A. (1975). The experimental contusion injury of the spinal cord in sheep. Paraplegia, 12, 275.

Yeo, J. D., McKenzie, B., Hinwood, B. \& Kidman, A. (I976). Treatment of paraplegic sheep with hyperbaric oxygen-a preliminary report. Med. F. of Aust. 1, 538-540.

Zivin, J. A., Doppman, J. L., Reid, J. L., Tappaz, M. L., SaAvedra, J. M., Dopin, I. J. \& JACOBowitz, D. M. (I976). Biochemical and histochemical studies of biogenic amines in spinal cord trauma. Neurology, 26, 99-107.

\section{General Discussion}

Dr SANDLER (Canada). I'd just like to ask you what measures you took to randomise your trial and use double blind techniques to evaluate the mode of control.

DR YEO. To this extent, the series was consecutive; sheep were taken and they weren't truly randomised perhaps to satisfy your critical mind, but I can say that when we came to analyse the clinical results the examiner did not know whether the animal fitted into the control or treated group.

Dr SANDLER. The selection of the animals was not randomised in the true sense.

DR YeO. Yes.

DR F. W. Meinecke (Germany). Dr Yeo, reviewing the literature of the last Io years, I can't tell you exactly who it was but I remember I have in mind some warning against the use of hyperbaric oxygen in spinal cord injuries and spinal cord lesions. I'm quite sure you probably know the author, but what do you feel about that. As far as I can remember the warning was that hyperbaric oxygen can produce further necrosis.

DR YEO. One of the reasons for presenting this paper was to hear if anyone in fact had used hyperbaric oxygen in man. I was not aware of any number of people that had been put into the chamber. We do know of course that hyperbaric oxygen can in fact influence cerebral and presumably spinal cord blood flow to the extent that it might diminish it, and there have been those who have studied that in detail, Kelly being one of them, but in the traumatised cord you've got a different haemodynamic state to what you have in normal blood flow. We believe that the hyperbaric oxygen just simply moves oxygen across the area where you've got compromised nervous tissue which is going to be progressively damaged by whatever toxic process that is going on there, and that it 
simply holds the nervous tissue in the potentially ischaemic area until the blood flow resumes some level which is going to maintain tissue. I don't know whether anyone, $\mathrm{Mr}$ Chairman, can report on the use clinically of hyperbaric oxygen.

Dr ERIC NoCCI (U.S.A.). If you give hyperbaric oxygen at 5 atmosphere pressure to normal rats you can actually make them paraplegic, and the cord would look as bad as $500 \mathrm{~g}$. I don't know what the atmosphere was that you gave.

DR Yeo. You said 5 atmosphere?

DR Nocci. Five atmospheres.

DR YeO. We've only used 3 atmospheres and we intend to use it in man at 2.5 atmospheres.

DR NochI. Well this is a finding that has been reported and we have found it to be true if you carry it through for 2 to 3 weeks. With respect to treatment I don't know how many injections of alphamethylparatyrosine you gave.

DR YEO. Just one, over 75 minutes. It was given at dosage intravenously of I 50 milligrams per kilogram.

DR NochI. And you found that to be more efficacious than methylprednisolone?

DR YEo. Yes.

DR Nochi. Can you give us a reason for it.

DR YEo. Yes, we've looked at the microscopy and its been of interest to us that looking at the microscopy the swelling of the spinal cord does not appear to be basically due to extracellular fluid. Looking at it on light microscopy it looks to us as though the swelling is due to congestion, extravasation and intracellular swelling. The periaxonal space which is an accepted artefact for light microscopy using paraffin sections is much greater increased and it seems to us that the swelling of the cord is almost intracellular and perhaps this is the reason why steroids don't appear to have any effect.

DR NochI. May I go on once more. I think this is very important because it has to do with ischaemia and oedema. We tried alpha-methyl prednisolone alone, it did not help, but when we tried it with amicar, which is ipsalonamenocoprobic acid, it's a membrane stabilising and antifibrinitic agent, both of them together were very efficacious, but each one alone was not helpful.

DR Flanigan (U.S.A.). Did I understand you correctly that the steroids were administered intrathecally?

Dr Yeo. Yes.

DR FLANIGAN. I would raise the question with you that material introduced in that fashion does not reach systemic circulation and on that count you would not get the usual and rapid immunological as well as anti-inflammatory effect of steroids as you would get it if it were administered intravenously. Was there a reason for selecting that route of administration?

DR YEO. We selected it in that way because it was administered in the particular form as dephamedrol, our argument being that for this reason we believed that the blood supply would be deficient, that we would deposit steroid in the region of the injured tissue within the subarachnoid space. Your comment is accepted. It may not be the best way of administering steroids.

ChalRman. Has anybody any comment then on administering hyperbaric oxygen to human spinal cord injured patients, from their own experience.

Mr HARRIS (G.B.). Some years ago when hyperbaric oxygen was popular in the news, we had the opportunity of using this chamber, and the whole chamber-you operated inside the chamber-in Glasgow, and one of our staff went through and spent a year there doing experimental studies in man, mainly strokes, head injuries and spinal injuries and with no obvious benefits, and I think this is what has happened with the use of hyperbaric oxygen clinically, that as far as I understand it there are only two situations where it's of help, one is gas gangrene and the other is carbon monoxide poisoning.

ChaIrman. Thank you, Mr Harris. 